\title{
Effects of a nonnative habitat-forming species on mobile and sessile epifaunal communities
}

\author{
Kirsten Sellheim ${ }^{1, *}$, John J. Stachowicz ${ }^{1}$, R. Cameron Coates ${ }^{2}$ \\ ${ }^{1}$ Section of Evolution and Ecology, University of California, 2320 Storer Hall, Davis, California 95616, USA \\ ${ }^{2}$ Center for Marine Biotechnology and Biomedicine, Scripps Institution of Oceanography, \\ University of California San Diego, 9500 Gilman Dr. MC 0212, La Jolla, California 92093-0212, USA
}

\begin{abstract}
Native and exotic sessile invertebrates can act as habitat modifiers and influence the diversity and composition of associated epifaunal communities. Theory and empirical research predict that greater habitat structural complexity will generally result in higher abundance, richness, and diversity of epifaunal species. We evaluated the impact of a recently introduced, structurally complex bryozoan, Watersipora subtorquata, by comparing its associated epifaunal communities with those of primary substrate, other habitat modifiers (tunicates and mussels), and structurally similar mimics. Community composition differed between Watersipora and other treatments for both mobile and sessile epifaunal communities, but species richness and diversity were significantly higher on Watersipora for mobile animals only. Differences in mobile community composition and diversity were driven by polychaete worms, which were found in greater abundance and higher diversity in Watersipora. Crustaceans, although equally abundant, were more evenly distributed across treatments. Sessile epifaunal communities differed little in richness or abundance among treatments, suggesting that while Watersipora provides biogenic surfaces for colonization that adequately compensate for the primary substrate it exploits, its high structural complexity does not correspond to an increase in sessile epifaunal abundance relative to less complex habitat modifiers. Our results suggest that neutral or facilitative effects of exotic species may be common; the strength and direction of the impact of a novel habitat-forming species on epifaunal communities will depend on the quality of the resource it provides, the strength of ecological interactions between habitatforming species and epifauna, epifaunal habitat preferences, and whether habitat is a limiting resource for a particular species or group.
\end{abstract}

KEY WORDS: Epifauna - Exotic species - Habitat complexity $\cdot$ Habitat engineer $\cdot$ Watersipora subtorquata

\section{INTRODUCTION}

Numerous studies document the negative impacts of exotics on the abundance or distribution of particular native species and the functioning of entire ecosystems (McCarthy et al. 2006, Ling 2008, Rilov \& Crooks 2008). The influence of a nonnative species on an invaded community is often greater when it performs a novel function in the community, because it is more likely to initiate cascading effects on multiple species (Simberloff 1995, Parker et al. 1999, Crooks 2002,
Kochmann et al. 2008). Partly due to the severe impact of a few devastating invasions, most research on the impact of nonnative species has focused on antagonistic interactions between nonnatives and natives (Parker et al. 1999, Grosholz et al. 2000, Ruiz et al. 2000, Stachowicz et al. 2002, Levine et al. 2003, Yurkonis et al. 2005). While these interactions are certainly important, a growing body of literature suggests that positive interactions may be equally important, both in general (e.g. Stachowicz 2001, Bruno et al. 2003) and specifically for invasive species (Bruno et al. 2005, 
Rodriguez 2006, Heiman et al. 2008). Exotic species that provide biogenic habitat for epifaunal organisms present an opportunity to explore the ways in which facilitation by nonnative organisms can impact community structure (Crooks 2002).

Marine invertebrate 'fouling' communities found in bays and harbors worldwide provide an especially tractable system for studying the relationships between mobile and sessile epifauna and their hosts because they often have a high diversity of both native and nonnative habitat-forming species that provide biogenic structure on an otherwise flat substrate. Fouling communities are composed of subtidal organisms that colonize substrate created by the submerged portions of floating docks and ships. Ship hulls and ballast water act as vectors for transporting adult and larval invertebrates from port to port, often over great distances (Ruiz et al. 2000), sometimes resulting in the establishment of new populations. Because of this colonization, habitat-forming sessile species in the fouling community are composed of a patchwork of native and nonnative tunicates, bryozoans, mussels, and hydroids. Many of these species have rigid shells, tests or skeletons on which other sessile species can settle and which mobile species can exploit as a refuge from predators.

An exotic habitat provider may increase the abundance or diversity of the epifaunal community if it provides a limited, novel, or superior resource (Jones et al. 1997, Hedge \& Kriwoken 2000, Rodriguez 2006). Many studies highlight the importance of structural complexity of a habitat in determining the abundance and diversity of associated mobile epifauna (Orth et al. 1984, Martin-Smith 1993, Beck 2000, Chemello \& Milazzo 2001, Grabowski \& Powers 2004). If mobile taxa exhibit habitat preferences, structural complexity may also influence the species composition of the epifaunal community (Perrett et al. 2006, Heiman et al. 2008). If a sessile host presents a better-quality habitat by providing more space, food, or a refuge from predators, it may support a higher diversity of species and greater abundance of mobile epifauna.

Substrate for settlement and growth is generally considered the limiting resource for sessile species in fouling communities, and competition for this space is the dominant biotic interaction (Stachowicz et al. 2002). As sessile invertebrates compete for space, they often grow vertically off the substrate, potentially creating new and distinct habitat for sessile epifaunal organisms. The use of biogenic habitat by sessile epifauna is less well understood than use by mobile epifauna, but can be mediated by factors such as habitat specialization, competition, and predation risk (Biernbaum 1981, Hacker \& Madin 1991, Russo 1991, Chemello \& Milazzo 2001, Kochmann et al. 2008). Due to competi- tion for spatial and trophic resources, some sessile invertebrates have physical, mechanical or chemical means of deterring settlement or evicting recruits of other sessile species (Wahl 1989, Krug 2006). Additionally, many larval sessile invertebrates have settlement preferences, which may lead to avoidance or aggregation of certain species (Buss 1981, Grosberg 1981, Osman \& Whitlatch 1995). The relative influence of each of these factors can generate complex and species-specific predictions about the abundance, diversity and structure of sessile epifaunal communities living on these habitat providers (Crooks 2008).

Most previous studies that have reported positive effects of nonnative habitat-forming species on native fauna are in systems in which no habitat-forming species existed prior to the invasion, such as mangroves, eelgrass, mussels, and tube-building polychaetes creating above-ground structure on relatively featureless sandy shores or mudflats (Schwindt \& Iribarne 2000, Crooks 2008 for review). There have been a few studies of nonnative habitat-forming species in systems in which native habitat-forming species co-occur. However, these studies compared epifaunal communities associated with nonnatives to those generated by bare space and structurally equivalent mimics only (Crooks 1998, Holloway \& Keough 2002) or native species of very similar complexity (Wikström \& Kautsky 2004). In addition, these studies frequently focused on a single type of epifaunal community (mobile or sessile), probably because interactions between epifauna and their hosts are likely to differ for mobile and sessile taxa. For example, a sessile organism such as a colonial tunicate or epiphytic algae may utilize resources similar to those of its host or physically overgrow it, resulting in a negative interaction (competition) between the 2 organisms (Harder 2009). In contrast, mobile epifauna may have a negligible impact on a sessile host due to their small size and different trophic requirements. Indeed, mobile epifauna may even benefit their host by removing sessile epibionts (e.g. Stachowicz \& Whitlatch 2005). A facilitative relationship may therefore be more likely between mobile epifauna and a habitatforming species, provided that the epifaunal species does not consume its host (Taylor \& Steinberg 2005). However, the overall impact of nonnative sessile organisms can only be understood if the effects on both mobile and sessile epifauna are examined.

The aim of this study was to determine the impact of a nonnative bryozoan (Watersipora subtorquata) on an epifaunal fouling community. Watersipora is a west Pacific species that arrived in southern California in the mid-1900s. It began spreading north around 1980 and was first recorded in Bodega Harbor in 1994 (Carlton \& Ruiz 2005). Because Watersipora is resistant to antifouling paint and many species are able to recruit 
onto its surface, it has been implicated as a vector for the spread of other nonnative sessile species (Floerl et al. 2004). Watersipora is more structurally complex than other dominant species in this community, and presents a novel habitat for both mobile and sessile epifauna. In separate experiments, we compared mobile and sessile epifaunal assemblages on experimentally deployed Watersipora with those of other native and nonnative habitat providers (the solitary sea squirt Ascidia ceratodes and the mussel Mytilus galloprovincialis), mimics of varying complexity, and primary substrate, and tested for differences in abundance, diversity, and community composition.

\section{MATERIALS AND METHODS}

Study system. The fouling community in Bodega Bay, California, USA is composed of native and nonnative sessile species including tunicates, bryozoans, hydroids, and molluscs. For these experiments, we focused on 2 nonnative species (Watersipora subtorquata, Mytilus galloprovincialis) and 1 native species (Ascidia ceratodes) that have well-established populations within the bay, are long lived ( $>1 \mathrm{yr}$ ) relative to the other species that use them for habitat, and provide varying degrees of habitat complexity. Watersipora is a colonial bryozoan. While it sometimes grows a single encrusting layer, it often produces structurally complex colonies of folded sheets of calcium carbonate zooids that generate numerous interstitial spaces, providing abundant potential settlement substrate for sessile epifauna and potential refuge for mobile epifauna. Compared to Watersipora, Mytilus (a bivalve mollusc) and Ascidia (a solitary sea squirt) each form monospecific aggregations of multiple individuals that have lower structural complexity and create fewer (but larger) interstitial spaces between individuals within a cluster of organisms. Due to differences in recruitment, life history, and survey methods between mobile and sessile epifauna, separate experiments were conducted for each epifaunal group.

Expt 1: mobile epifauna. We created monocultures of the 3 primary space occupiers (Ascidia ceratodes, Mytilus galloprovincialis, Watersipora subtorquata) by attaching colonies or groups of individuals with similar volumes (approximately 600 to $800 \mathrm{~cm}^{3}$ ) to $10 \times 10 \mathrm{~cm}$ PVC settlement tiles with rubber bands (Watersipora) or glue (Mytilus), or by collecting them as adults that are already attached to $10 \times 10 \mathrm{~cm}$ tiles (Ascidia). Although the treatments generally covered most of the tile to which they were attached, a small amount of exposed tile surface was also available for recruitment. In addition to the 3 live treatments, we used dead Watersipora colonies as structurally complex mimics to separate the effect of structural complexity alone from that of the living organism. We also deployed small $(10 \times 10 \mathrm{~cm})$ and large $(30 \times 30 \mathrm{~cm})$ PVC tiles as primary substrate control treatments. The total surface area of the large tile was comparable to that of the Ascidia and Mytilus treatments.

Prior to deployment, we estimated the surface area of each colony or cluster by running a string around the structure, into all of the interstitial spaces, starting and ending at the base. After taking 5 measurements each in a north-south and an east-west direction, we calculated the mean of the 5 measurements for each direction and multiplied the 2 means to get an estimate of the total surface area of the treatment. Because all treatments (except the large tile) fit within a $10 \times 10 \mathrm{~cm}$ area of primary substrate and occupied a similar volume, we report structural complexity as the amount of surface area per $10 \times 10 \mathrm{~cm}$ area of primary substrate.

We deployed 10 replicates of each of the 6 treatments at the Spud Point Marina in Bodega Bay in midAugust 2005. By starting the mobile experiment later in the summer, we avoided part of the season of maximum recruitment and growth by sessile epifauna, allowing us to maintain habitat treatments, although some recruitment occurred over the course of the experiment. We fastened one replicate of each treatment to a rack made of PVC pipe (except the large tile, which was hung separately due to its large size) and hung the rack facing down $\sim 1 \mathrm{~m}$ below the water surface. Racks were checked twice a week for damage or loss. In late October 2005, we collected all treatments and their associated mobile epifauna by placing a Ziploc bag around each plate and removing the plate from the rack while still submerged. Using this method, we collected mobile epifauna attached to both the treatment itself and the tile to which the treatment was affixed. Bags were transported in coolers to Bodega Marine Laboratory, where all mobile organisms were removed, fixed in formalin and transferred to $70 \%$ ethanol for identification. Mobile epifauna included polychaete worms, crustaceans, molluscs, platyhelminths, oligochaetes and sipunculans. In most cases, specimens were identified to species using available taxonomic keys (Fauchauld 1977, Carlton 2007).

Expt 2: sessile epifauna. To examine the effect of different habitat providers on the sessile epifaunal community, we ran a second (longer) experiment from late April to late October 2007 ( 6 mo) to allow interactions among sessile species to develop over a full recruitment season. This experiment included 10 replicates of each of the 3 monoculture treatments and 2 bare panels as described in Expt 1, as well as inert structural mimics for each species. We created structurally complex Watersipora mimics by tying to- 
gether eight $10 \times 10 \mathrm{~cm}$ pieces of window screen and dipping them in wax. The resulting 'colony' was glued to a $10 \times 10 \mathrm{~cm}$ tile. Mytilus mimics were composed of 4 dead mussel shells that were filled with epoxy and glued to tiles, while Ascidia mimics were composed of tubes of window screen that were filled with silicon sealant and glued to tiles. As in Expt 1, $10 \times 10$ and $30 \times 30 \mathrm{~cm}$ tiles were deployed as primary substrate control treatments with low and high surface area, respectively. To test whether the texture of the window screen surface of the Watersipora and Ascidia mimics affected recruitment of larvae of sessile epifauna, we compared the $10 \times 10 \mathrm{~cm}$ tile treatments to an additional control treatment composed of a flat piece of wax-dipped window screen that was glued to a $10 \times 10 \mathrm{~cm}$ PVC tile. The screen/wax tile controls never differed significantly from small tiles in abundance, richness, or diversity (all p > 0.05) so these data are not presented.

We assembled individual replicates into blocks on PVC racks and deployed them using the methods described in Expt 1. We deployed all treatments at the start of the sessile recruitment season (late April), and recorded cover $\left(\mathrm{cm}^{2}\right)$ of all species of sessile epifauna in late October, when recruitment slowed to winter levels. In previous experiments (Nydam \& Stachowicz 2007), this duration was sufficient for all space to be colonized and for interactions among sessile species to occur. We estimated the total cover of each species using a transparent plexiglass sheet that was divided into $1 \times 1 \mathrm{~cm}$ squares. We repeatedly positioned the sheet at various angles on the substrate such that all surfaces on the treatment were included in the estimate of epifaunal cover, but excluded sessile epifauna attached to the tile itself for both live and mimic treatments. This method was used in addition to the string method described in Expt 1 to calculate the initial surface area of each replicate prior to deployment. For live Ascidia and Watersipora treatments, the initial surface area of each of the primary species was subtracted from the final observed cover so that only growth or recruitment during the experiment was used in calculating the epifaunal abundance of said species in these treatments.

Data analysis. Abundance, species richness, and diversity were compared using ANOVA with Tukey's post hoc test. We tested ANOVA assumptions of normality with the Shapiro-Wilk test and homogeneity of variances with Levene's test. Data that did not meet the assumptions were transformed appropriately prior to analysis. The block (rack) effect was only significant in ANOVA comparisons of sessile organism abundance, but it was retained in the model for all analyses (Table S1 available as supplementary material at: www.int-res.com/articles/suppl/m398p069_app.pdf).
We performed multivariate analyses with the PRIMER software package (Clarke \& Warwick 1994). Nonparametric multi-dimensional scaling (nMDS) was used to compare community composition among treatments for mobile and sessile epifauna. Species abundances were transformed to proportions for each sample, and the Bray-Curtis similarity matrix was used to compare species composition among samples. Stress measures the goodness of fit of the regression of the Bray-Curtis similarity matrix onto the 2-dimensional nMDS plot. Smaller stress values indicate that the distances between points on the nMDS plot closely match the similarity values from the Bray-Curtis matrix.

An analysis of similarities (ANOSIM) was then performed to conduct pairwise comparisons of similarity in community composition between treatments. The $\mathrm{R}$ statistic compares similarity within treatments to similarity between treatments using values from the BrayCurtis matrix. The significance level is based on a distribution created by random permutations of the Bray-Curtis matrix.

Finally, the similarity percentage technique (SIMPER) was used to determine the relative contribution of each species to the differences between groups. For each treatment, we reported the average relative proportion of the species that explain $90 \%$ of the dissimilarity among treatments.

\section{RESULTS}

\section{Mobile epifauna}

We identified 76 mobile taxa, with a total of 31162 ind. Polychaete worms and crustaceans were the most abundant and species-rich groups. Platyhelminths, oligochaetes, sipunculans, molluscs, and fishes were also present (Table S2 available as supplementary material at: www.int-res.com/articles/suppl/m398p069 _app.pdf).

Comparing surface area per unit of primary substrate across all treatments was not possible because the lack of variance in the small and large tile control treatments violated the ANOVA assumption of homogeneity of variances ( $p<0.05$, Levene's test). Therefore, the tile treatments were eliminated from statistical analyses of structural complexity (Fig. 1A). The ANOVA revealed significant differences in surface area across the remaining 4 treatments (Table S1). Surface area was significantly higher in the live and mimic Watersipora treatments than in all others, and the Ascidia treatment had significantly lower surface area than the Mytilus treatment (Fig. 1A).

There were some significant differences in mobile epifaunal abundances across treatments (Table S1). 

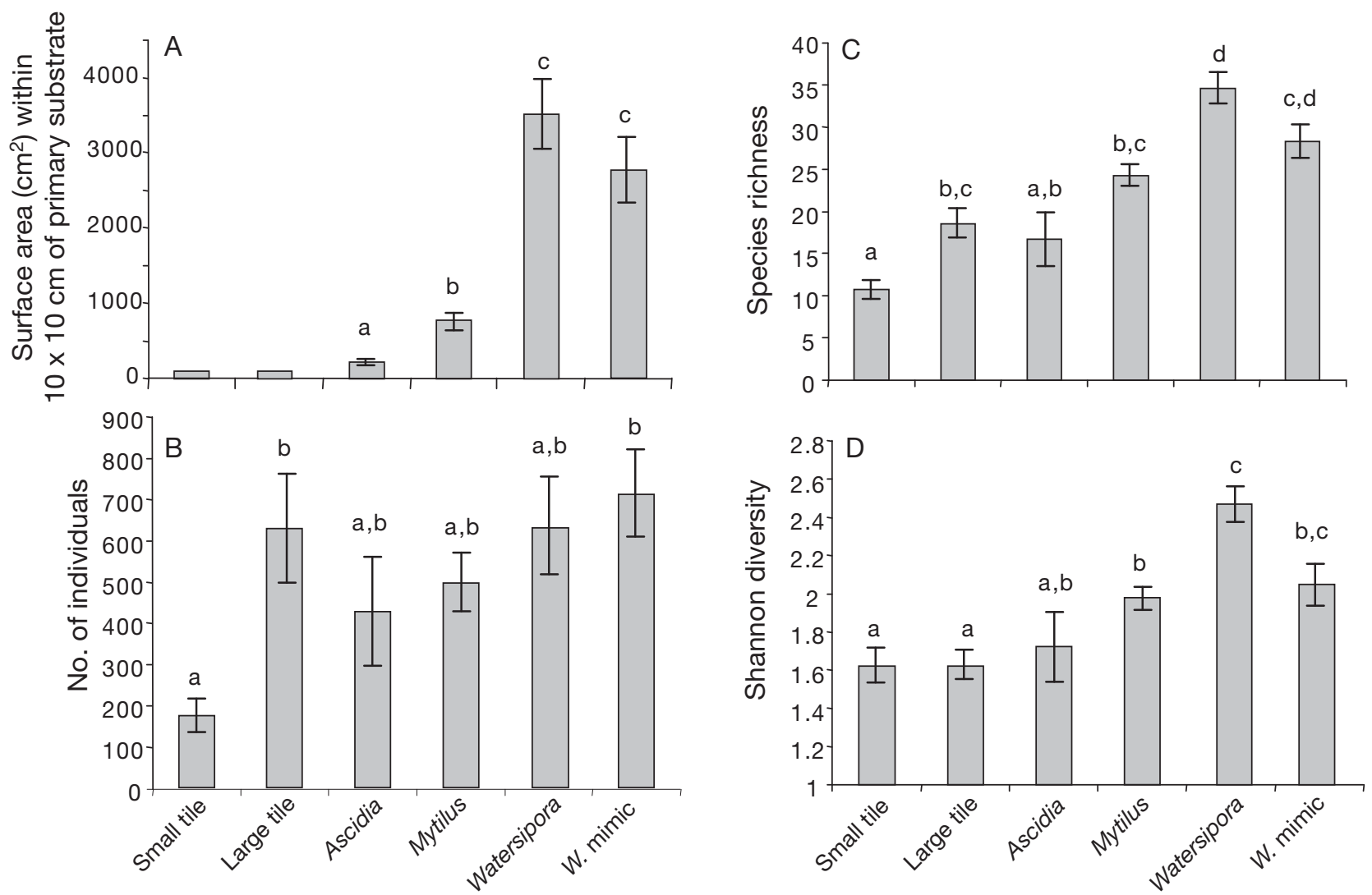

Fig. 1. (A) Surface area, (B) abundance, (C) richness and (D) diversity ( \pm 1 SE) of mobile epifauna. Data were analyzed using ANOVA. Different letters above each bar indicate significantly different means (Tukey's post-hoc test, $p<0.05$ )

Epifaunal abundance was significantly lower on the small tiles than on the large tile and the Watersipora mimic treatments, but abundances were similar across all other treatments (Fig. 1B). Species richness and diversity also differed across treatments (Table S1). Both were highest in live Watersipora followed by the Watersipora mimic and live Mytilus treatments (Fig. 1C,D). Richness and diversity were lowest in the small and large tiles and live Ascidia treatments. Because abundances were similar across treatments (except for the small tile), differences in species richness do not appear to be due to the presence of more individuals in structurally complex treatments.

The analysis of similarities (ANOSIM) showed significant overall differences in community composition (global $p=0.001$, Table 1), and the qualitative impressions from the nMDS plot suggest that many of the treatments with different levels of structural complexity also had significant differences in community composition (Fig. 2). Watersipora and its mimic overlapped substantially, but were distinct from the other treatments, which all overlapped with each other (Fig. 2). Small and large tile communities differed significantly from both live and mimic Watersipora treatments (ANOSIM, $p<0.05$, Table 1), but there were no differences in pairwise comparisons between small and large tiles (low complexity treatments), Ascidia and Mytilus (moderate complexity treatments), or Watersipora and its mimic (high complexity treatments)

Table 1. ANOSIM for mobile epifauna: pairwise comparisons of dissimilarity between treatments (R statistic) and significance level. Insignificant pairwise differences are not reported

\begin{tabular}{|lcc|}
\hline Pairwise comparison & $\begin{array}{c}\mathrm{R} \\
\text { statistic }\end{array}$ & $\begin{array}{c}\mathrm{p} \\
\text { value }\end{array}$ \\
\hline Global & 0.289 & 0.001 \\
Small tile, Mytilus & 0.184 & 0.012 \\
Small tile, Watersipora & 0.546 & 0.001 \\
Small tile, Watersipora mimic & 0.230 & 0.018 \\
Large tile, Ascidia & 0.372 & 0.006 \\
Large tile, Mytilus & 0.250 & 0.012 \\
Large tile, Watersipora & 0.547 & 0.001 \\
Large tile, Watersipora mimic & 0.420 & 0.001 \\
Ascidia, Watersipora & 0.537 & 0.001 \\
Ascidia, Watersipora mimic & 0.194 & 0.027 \\
Mytilus, Watersipora & 0.533 & 0.001 \\
Mytilus, Watersipora mimic & 0.272 & 0.002 \\
\hline
\end{tabular}


Small tile Large Tile Ascidia Mytilus

- Watersipora $\triangle W$. mimic

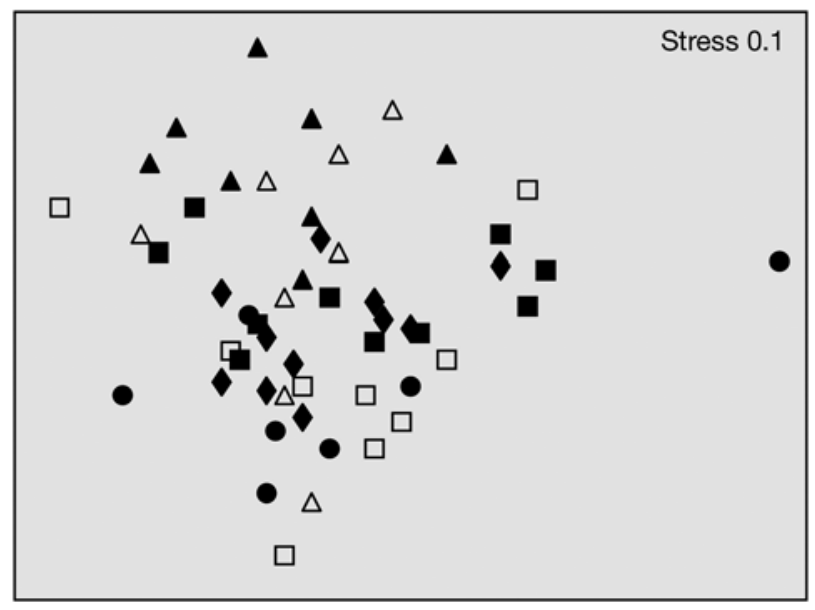

Fig. 2. Nonmetric multi-dimensional scaling (nMDS) plot of mobile epifaunal community composition. The plot was created using a Bray-Curtis community similarity matrix of species abundances

(ANOSIM, all p > 0.05, Table 1), suggesting that substrate complexity may have affected patterns of community composition across the treatments.

The results of the SIMPER analysis indicated that the relative proportions of crustaceans (primarily amphipods) and the polychaete Nereis latescens drove many of the similarities in community composition in the less complex treatments (Table 2). The higher abundance and diversity of polychaete taxa found in the Watersipora treatments appear to have generated the dissimilarity in community composition between these treatments and those of lower complexity (Table 2).

\section{Sessile epifauna}

A total of 20 sessile epifaunal taxa established on our plates after the second, 6 mo experiment. We identified 16 of these to species and an additional 2 to genus (Table S3). Taxa present included tunicates, bryozoans, sponges, and cnidarians (Table S3 available as supplementary material at: www.int-res.com/articles/ suppl/m398p069_app.pdf).

As with the mobile experiment, the complexity (total surface area per unit of primary substrate) differed across treatments (Table S3 available as supplementary material at: www.int-res.com/articles/suppl/m398 p069_app.pdf). Live Watersipora had significantly higher complexity than all other treatments, followed by its mimic (Fig. 3A). Structural complexity was lower for live Mytilus, live Ascidia, and their mimics and was similar across these 4 treatments (Fig. 3a).

Although there were differences in complexity across treatments, there was no obvious relationship between a host's complexity and sessile epifaunal abundance (amount of surface area covered by epifauna), species richness, or diversity (Table S1, Fig. 3A-D). By the end of the experiment, Watersipora and its mimic were the only treatments with substantial bare space (K. Sellheim pers. obs.). The total cover of sessile epifauna was significantly higher in the large tile treatment than in all other treatments, despite the higher total surface area of all habitat-forming treatments (Fig. 3A,B). Apart from the large tile treatment, sessile species richness did not vary among any of the other treatments except that the small tiles had lower richness than live Ascidia (Fig. 3C). Species diversity was slightly higher in live Ascidia than in other treatments, but this difference was only statistically signifi-

Table 2. SIMPER analysis for mobile epifauna. Values indicate the mean proportion of total abundance for a given species within a treatment. -: species was not present in a treatment. Only species that contributed significantly to the dissimilarities across treatments are listed (SIMPER, cutoff $90 \%$ )

\begin{tabular}{|c|c|c|c|c|c|c|c|}
\hline Taxon & Species & $\begin{array}{l}\text { Small } \\
\text { title }\end{array}$ & $\begin{array}{l}\text { Large } \\
\text { title }\end{array}$ & Ascidia & Mytilus & Watersipora & $\begin{array}{c}\text { Watersipora } \\
\text { mimic }\end{array}$ \\
\hline \multirow[t]{4}{*}{ Amphipoda } & Ampithoe spp. & 0.24 & 0.23 & 0.23 & 0.29 & 0.13 & 0.22 \\
\hline & Corophium spp. & 0.23 & 0.06 & 0.19 & 0.12 & 0.05 & 0.11 \\
\hline & Caprella mutica & 0.14 & 0.25 & 0.16 & 0.14 & 0.07 & 0.07 \\
\hline & Mayerella banksias & - & 0.04 & - & - & - & - \\
\hline Isopoda & Idotea sp. 1 & 0.05 & - & 0.06 & - & 0.02 & 0.05 \\
\hline Decapoda & Taneis sp. & - & - & 0.06 & 0.06 & 0.05 & 0.04 \\
\hline Copepoda & Cyclopoida & - & - & - & 0.03 & 0.04 & 0.05 \\
\hline \multirow[t]{7}{*}{ Polychaeta } & Nereis latescens & 0.25 & 0.30 & 0.14 & 0.18 & 0.22 & 0.18 \\
\hline & Lumbrineris sp. 1 & - & - & - & - & 0.04 & - \\
\hline & Lumbrineris sp. 2 & - & - & - & - & 0.02 & - \\
\hline & Neoleprea californica & - & - & - & - & 0.02 & - \\
\hline & Harmothoe imbricata & - & - & - & - & 0.02 & - \\
\hline & Dorvillea longicornis & - & - & - & - & 0.15 & 0.13 \\
\hline & Ophelia sp. & - & - & - & 0.02 & - & 0.04 \\
\hline
\end{tabular}



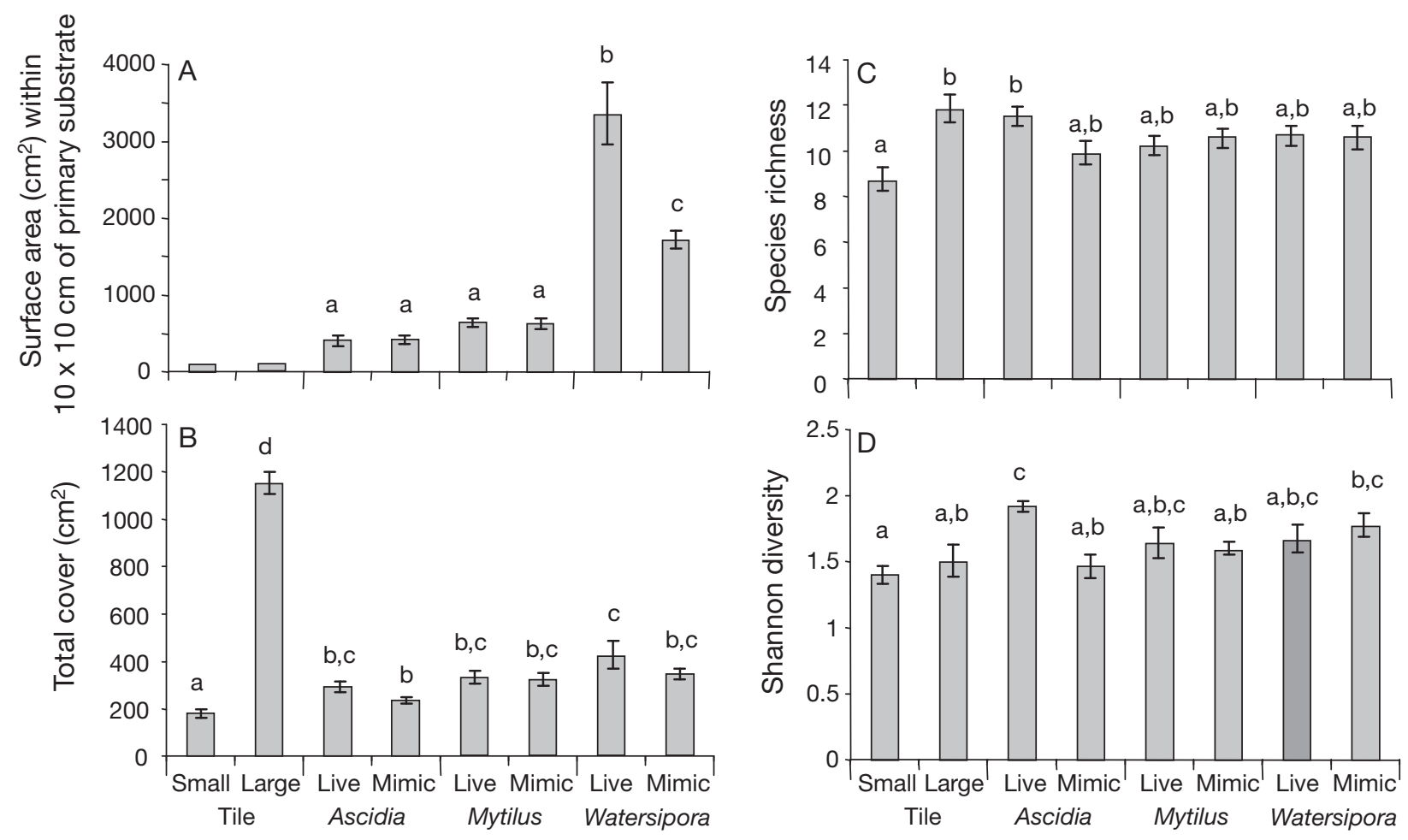

Fig. 3. (A) Surface area, (B) total cover, (C) richness and (D) diversity ( \pm 1 SE) of sessile epifauna. Data were analyzed using ANOVA. Different letters above each bar indicate significantly different means (Tukey's post-hoc test, $\mathrm{p}<0.05$ )

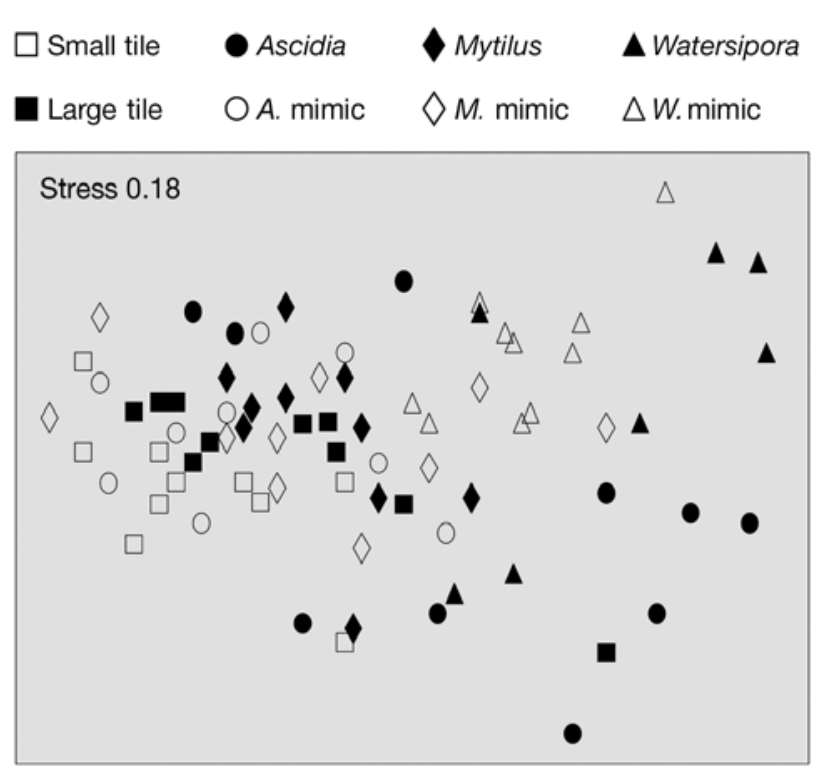

Fig. 4. Nonmetric multi-dimensional scaling (nMDS) plot of sessile epifaunal community composition. The plot was created using a Bray-Curtis community similarity matrix of species abundances

cant in comparison with both tile treatments and Ascidia mimics (Fig. 3D).

The nMDS plots and ANOSIM analysis indicated that sessile epifaunal communities were significantly
Table 3. ANOSIM for sessile epifauna: pairwise comparisons of dissimilarity between treatments (R statistic) and significance level. Insignificant pairwise differences are not reported

\begin{tabular}{|lcc|}
\hline Pairwise comparison & $\begin{array}{c}\mathrm{R} \\
\text { statistic }\end{array}$ & $\begin{array}{c}\mathrm{p} \\
\text { value }\end{array}$ \\
\hline Global & 0.296 & 0.001 \\
Small tile, Ascidia & 0.468 & 0.001 \\
Small tile, Mytilus & 0.208 & 0.007 \\
Small tile, Watersipora & 0.762 & 0.001 \\
Small tile, Watersipora mimic & 0.784 & 0.001 \\
Large tile, Ascidia & 0.345 & 0.004 \\
Large tile, Watersipora & 0.595 & 0.001 \\
Large tile, Watersipora mimic & 0.609 & 0.001 \\
Ascidia, Ascidia mimic & 0.383 & 0.003 \\
Ascidia, Mytilus & 0.305 & 0.002 \\
Ascidia, Mytilus mimic & 0.286 & 0.003 \\
Ascidia, Watersipora & 0.434 & 0.001 \\
Ascidia, Watersipora mimic & 0.400 & 0.001 \\
Ascidia mimic, Watersipora & 0.678 & 0.001 \\
Ascidia mimic, Watersipora mimic & 0.641 & 0.001 \\
Mytilus, Watersipora & 0.618 & 0.001 \\
Mytilus, Watersipora mimic & 0.499 & 0.001 \\
Mytilus mimic, Watersipora & 0.455 & 0.003 \\
Mytilus mimic, Watersipora mimic & 0.391 & 0.001 \\
Watersipora, Watersipora mimic & 0.224 & 0.018 \\
\hline
\end{tabular}

dissimilar in composition among the treatments (Fig. 4, stress $=0.1$; Table 3, global $p=0.001$ ). Live Mytilus differed from the small tile but not the large tile treatment, and the Mytilus mimic did not differ from either 
tile treatments (Table 3). There were significant differences in community composition between the tile treatments and the live Ascidia treatment, but not between tiles and Ascidia mimics (Table 3). Live Ascidia and Watersipora treatments were both dissimilar to all other treatments (Table 3). The SIMPER results revealed that differences in sessile community composition between the live and mimic Watersipora treatments and the other treatments were driven primarily by differences in the relative abundance of Ascidia and Watersipora that had grown or recruited after the start of the experiment (Table 4). Although the relatively high proportion of epifaunal Watersipora on the live Watersipora treatment is likely to be partly due to the growth of the colony that we transplanted to the panel, mimic Watersipora treatments also had a larger proportion of Watersipora cover compared to other treatments (Table 4).

\section{DISCUSSION}

\section{Mobile epifauna}

Differences in the mobile assemblages associated with live and mimic Watersipora were slight, suggesting that the physical form of Watersipora, rather than any biological properties, is the principal reason for Watersipora's effect on the mobile epifaunal community. The idea that a more complex habitat will harbor a greater diversity and abundance of mobile epifauna is well supported across marine and terrestrial systems (Martin-Smith 1993, Chemello \& Milazzo 2001, Grabowski \& Powers 2004, Schmidt \& Scheibling 2006). In the present study, although mobile epifaunal richness and diversity were significantly higher in high complexity treatments, abundance was not. This result suggests that the observed patterns of increased richness were not simply a function of higher numbers of individuals sampled on the Water- sipora treatments or a general reduction in predation pressure. Instead, we suggest that the effect of Watersipora on species richness was primarily the result of the creation of qualitatively different habitat rather than an increase in surface area per se.

The small size and depth of the interstitial spaces in Watersipora that led to high surface area measurements allowed the accumulation of sediments, generating novel sedimentary environments on what is mostly a hard substrate area. This novel habitat type was associated with an increased abundance and diversity of polychaete worms, which are normally found in sedimentary habitats, on live and mimic Watersipora relative to other treatments (Table 2). Watersipora's high complexity also provides mobile epifauna (crustaceans and polychaetes) with a superior refuge from highly mobile predators (fish and crabs) relative to less complex habitat in laboratory mesocosms (K. Sellheim unpubl. data). However, the abundance and diversity of crustaceans on Watersipora treatments were comparable to or lower than those of less complex treatments and primary substrate (Tables 2 \& A2). Structural complexity may increase predation on epifaunal species if predators are among the species that take refuge within the complex habitat. Indeed, many of the polychaetes we found in Watersipora are known predators of small invertebrates (Fauchald \& Jumars 1979). Thus, polychaete epifauna could cause decreases in amphipod abundance either through consumption or behavioral avoidance that offset the potential increased refuge value of Watersipora from fish predation. In fouling communities, smaller predators living within the habitat, such as polychaete worms, may be more abundant than larger predators, such as fishes or crabs (K. Sellheim pers. obs.) and therefore pose a greater risk to epifaunal prey, causing a shift among mobile epifauna to more open habitat. Indeed, the high density of caprellid amphipods observed on large panels devoid

Table 4. SIMPER analysis for sessile epifauna. Values indicate the mean proportion of total abundance for a given species within a treatment. -: species was not present in treatment. Only species that contributed significantly to the dissimilarities across treatments are listed (SIMPER, cutoff $90 \%$ )

\begin{tabular}{|lcccccccc|}
\hline Species & $\begin{array}{c}\text { Small } \\
\text { title }\end{array}$ & $\begin{array}{c}\text { Large } \\
\text { title }\end{array}$ & Ascidia & $\begin{array}{c}\text { Ascidia } \\
\text { mimic }\end{array}$ & $\begin{array}{c}\text { Mytilus } \\
\text { mimic }\end{array}$ & $\begin{array}{c}\text { Mytilus } \\
\text { mimersipora }\end{array}$ & $\begin{array}{c}\text { Watersipora } \\
\text { mimic }\end{array}$ \\
\hline Ascidia ceratodes & & & & & & & & \\
Botrylloides violaceus & 0.52 & 0.49 & 0.25 & 0.49 & 0.41 & 0.42 & 0.16 & 0.24 \\
Distaplia occidentalis & 0.09 & 0.12 & 0.11 & 0.17 & 0.16 & 0.18 & 0.10 & 0.15 \\
Ciona intestinalis & 0.09 & 0.11 & 0.09 & 0.09 & 0.07 & 0.07 & 0.10 & 0.09 \\
Diplosoma listerianum & 0.09 & 0.12 & 0.09 & 0.08 & 0.13 & 0.10 & 0.18 & -0.09 \\
Didemnum vexillum & 0.10 & 0.06 & - & - & - & 0.08 & - & - \\
Watersipora subtorquata & - & - & 0.07 & - & - & - & - & - \\
Bugula neritina & - & - & 0.08 & - & 0.10 & - & - & - \\
\hline
\end{tabular}


of any refuge suggests that predation by large mobile species such as fishes may be weak in this system (Table 2).

Although nonnative epifaunal species richness was too low to compare across treatments, it is notable that the nonnative species found in high abundance in the present study were crustaceans (Caprella mutica and 2 species of Corophium) that did not exhibit an obvious habitat preference (Tables 2 \& A1). Only 1 nonnative polychaete species was found in very low abundance in our study (Capitella capitata, total of 6 ind.), even though species richness was much higher for polychaete worms than for any other taxonomic group (Table A2), and crustaceans and polychaete worms were equally abundant. Many fouling community amphipods are highly mobile generalist feeders, and thus may be more likely to colonize the hulls of ships than burrowing, predatory polychaete worms. Amphipods also lack a free-living larval stage, potentially enhancing establishment of a population from one or a few gravid females. The patterns of high native and low nonnative polychaete abundance and diversity found in the present study suggest that polychaetes have more specific habitat preferences than crustaceans, perhaps limiting their rates of large-scale dispersal and establishment success.

\section{Sessile epifauna}

In contrast to the stark effect on mobile epifauna, the higher complexity of Watersipora and its mimic had no effect on overall abundance, richness or diversity of sessile epifauna (Fig. 3A-D), although there were distinct effects on the abundance of particular species. Still, there were few differences in these measures across any of the treatments in the sessile experiment, implying that all of the habitat-forming species and their mimics provide at least as much settlement surface as they occupy, preventing declines in abundance and richness associated with competition for space. While it is possible that competitive exclusion via overgrowth could occur between sessile epifaunal species if our experiment was extended over a longer period, the panels were exposed to settlement during the entire range of the peak recruitment times for all common species in the community (J. J. Stachowicz unpubl. data). The space on the bare panels was almost completely occupied by late July, allowing several months for competitive interactions to take place. Additionally, we surveyed the panels after recruitment had diminished in the autumn but before winter mortality began to occur - a time when the effects of competitive interactions are likely to be visible without the confounding effects of physio- logical stress of winter precipitation and colder temperatures.

A previous study in this ecosystem found that high Watersipora cover was positively correlated with species richness (Stachowicz \& Byrnes 2006), but we found no evidence that this relationship was causal. Because Watersipora is relatively slow growing, high Watersipora cover may be associated with patch age, and thus these patches may have had more time to accumulate species, leading to a noncausal relationship between Watersipora and total sessile species richness. Although other sessile species settle on large Watersipora colonies, the erect growth form of Watersipora appears relatively resistant to mortality from overgrowth by other species, and solitary and colonial tunicates that settled on the Watersipora treatments did not appear to spread or grow as quickly as those on other treatments (K. Sellheim pers. obs.). Nonnative species that actively limit recruitment or growth of sessile epifauna may have a competitive advantage over native species in the long term, especially species such as Watersipora with individual colonies that may persist over multiple years.

Although the richness and abundance of sessile epifauna differed little across treatments, multivariate analyses indicated that sessile assemblages associated with different basal species differed (Table 3, Fig. 4). Although there was no significant difference between the sessile epifaunal communities of Mytilus and its mimic, epifaunal assemblages on live Ascidia and Watersipora were distinct from both their mimics and primary substrate treatments (Table 3). Other studies have found that bacterial biofilms and chemical or behavioral deterrents can determine whether different epifaunal species are able to recruit and survive on different basal species (Buss 1981, Grosberg 1981, Osman \& Whitlatch 1995, Krug 2006). Sessile species that have coexisted for a long time may have evolved mechanisms for recruitment deterrence that are specific to an epifaunal species or functional group, and native sessile species may not be able to avoid overgrowth by a novel invader. For example, the native Ascidia had higher abundance of 2 invaders, Bugula neritina and Didemnum vexillum, than all other treatments (Table 4). While we did not address the specific mechanisms of epibiotic interactions, the observed differences in community composition in the live Ascidia and Watersipora treatments, both relative to one another and to mimics and primary substrate, suggest that settlement preferences, differential mortality and/or avoidance may be occurring for some taxa.

For example, there was clear evidence of intraspecific settlement facilitation in Watersipora, with greater increases in Watersipora epifaunal cover on Watersipora and its mimic than in other treatments (Table 4). 
This result is not surprising for live Watersipora treatments, as the growth of the basal organism likely provided some of the observed additional cover. However, the higher cover of epifaunal Watersipora on its mimic suggests that some aspect of the organism's structure increases recruitment and/or growth of this species. Preferential settlement near conspecifics is relatively common in sessile marine invertebrates (Buss 1981, Rodriguez et al. 1993), although this has not been demonstrated for Watersipora. Because intraspecific interactions among colonies may facilitate the production of vertical structure in this species (J. J. Stachowicz pers. obs.), it is possible that settlement enhancement might increase the structural complexity of Watersipora habitat, although this remains to be conclusively demonstrated.

\section{CONCLUSIONS}

Mobile epifaunal richness and diversity were highest on the nonnative bryozoan Watersipora subtorquata (Fig. 1C,D). The similarity in mobile epifaunal composition and richness between Watersipora and its mimic suggests that increased structural complexity, particularly the depth and small size of interstitial spaces, is likely the cause of differences among treatments. In contrast, for sessile epifauna, there were few differences in richness or abundance among treatments despite large differences in surface area per unit of primary substrate (Fig. 3A-C). In general, the primary space pre-empted by Watersipora appears to be compensated for by its biogenic surfaces for colonization, but Watersipora's high surface area does not provide more or novel habitat for sessile epifauna relative to less complex habitat-forming species. These results suggest that neutral or facilitative effects of exotic habitat providers on epifaunal assemblages may be at least as important as negative effects and need to be given greater consideration in the assessment of the net effects of exotic species on invaded communities.

Based on the findings of the present study, the effect of an introduced habitat provider on mobile species should be predictable based on the relative structural complexity of the invader and the identity of the particular mobile taxonomic group. For example, an introduced species with low complexity would be expected to decrease the diversity and richness of the regional mobile community if it displaces or reduces the abundance of a more complex sessile species or homogenizes formerly heterogeneous habitat. This may be occurring in areas where Didemnum vexillum, a colonial tunicate that produces large mat-like colonies, smothers other basal species and reduces abiotic heterogeneity (Bullard et al. 2007, but see Mercer et al.
2009). Watersipora subtorquata may also produce flat, encrusting colonies (Floerl et al. 2004), and in this form may decrease richness of mobile epifauna relative to other basal species. In contrast, if a nonnative has similar complexity as native species, it may have a negligible impact on mobile epifaunal richness and diversity, as has been observed in studies of epifaunal communities of invasive cordgrass and brown seaweeds invading areas where closely related native species also occur (Hedge \& Kriwoken 2000, Wikström \& Kautsky 2004). Our study suggests that the introduction of a highly complex nonnative such as $W$. subtorquata to systems dominated by native sessile species of low complexity is likely to increase local diversity and may change the overall community composition of mobile epifauna, in particular increasing the diversity of polychaete worms.

Because interactions between sessile epifauna and habitat-forming sessile species appear to depend less on general properties like structural complexity and more on species-specific interactions, predictions of how nonnative habitat providers will affect sessile epifaunal communities are more challenging. All the species in our experiment allowed the settlement of heterospecifics to some degree, but a nonnative species with greater ability to deter epifauna could cause a decline in species richness. For example, due to its physical and chemical defenses against epifaunal settlement, Ciona intestinalis lowered species richness in communities where it occurred (Blum et al. 2006). If epibionts harm the basal species on which they settle, this could lead to increased dominance by species that are resistant to settlement, although we have no evidence that any of the habitat-forming species in our study were harmed by their epibionts. In general, the outcome of interactions between habitat-forming species and associated sessile epifauna remains unclear, and likely depends on the basal species under consideration.

Although the introduction of exotic species may have a negative impact on local communities via predation or competitive interactions with native species, we show that nonnative species may also facilitate natives by providing a novel or limiting resource for epifaunal organisms. Although Watersipora exploits primary substrate, it also provides settlement space for sessile epifauna, mitigating its consumption of this limiting resource. In addition, by providing a novel habitat for mobile epifauna, Watersipora increases species richness and diversity of certain mobile taxa. Because nonnative habitat-forming species are ubiquitous in both marine and terrestrial environments, it is important to develop a more complete knowledge of both negative and positive interactions between an exotic species and the community it has invaded in order to understand its net effect on the community. 
Acknowledgements. We thank P. Reynolds, M. Young, A. Chaudoin, R. Best, K. Aquilino, K. Edwards, and M. Lundy for field assistance. We acknowledge a grant to R.C.C. from the UC Davis IGERT undergraduate research fellowship program and continued support from the National Science Foundation Biological Oceanography program. This research was conducted at Spud Point Marina and Bodega Marine Laboratory.

\section{LITERATURE CITED}

Beck MW (2000) Separating the elements of habitat structure: independent effects of habitat complexity and structural components on rocky intertidal gastropods. J Exp Mar Biol Ecol 249:29-49

Biernbaum CK (1981) Seasonal changes in the amphipod fauna of Microclona prolifera and associated sponges in a shallow salt-marsh creek. Estuaries 4:85-96

Blum JC, Chang AL, Liljesthrom M, Schenk ME, Steinberg MK, Ruiz GM (2006) The nonnative solitary ascidian Ciona intestinalis (L.) depresses species richness. J Exp Mar Biol Ecol 342:5-14

Bruno JF, Stachowicz JJ, Bertness MD (2003) Inclusion of facilitation into ecological theory. Trends Ecol Evol 18: 119-125

Bruno JF, Fridley JD, Bromberg KD, Bertness MD (2005) Insights into biotic interactions from studies of species invasions. In: Sax DF, Stachowicz JJ, Gaines SD (eds) Species invasions: insights into ecology, evolution, and biogeography. Sinauer, Sunderland MA, p 13-40

Bullard SG, Lambert G, Carman MR, Byrnes J and others (2007) The colonial ascidian Didemnum sp. A: current distribution, basic biology and potential threat to marine communities of the northeast and west coasts of North America. J Exp Mar Biol Ecol 342:99-108

Buss LW (1981) Group living, competition, and the evolution of cooperation in a sessile invertebrate. Science 213: 1012-1014

Carlton JT (2007) The Light and Smith manual: intertidal invertebrates from Central California to Oregon. University of California Press, Berkeley, CA

Carlton JT, Ruiz GM (2005) The magnitude and consequences of bioinvasions in marine ecosystems. In: Norse EA, Crowder LB, Soule ME (eds) Marine conservation biology. Island Press, Washington DC, p 123-148

Chemello R, Milazzo M (2001) Effect of algal architecture on associated fauna: some evidence from phytal molluscs. Mar Biol 140:981-990

Clarke KR, Warwick RM (1994) Change in marine communities: an approach to statistical analysis and interpretation. Natural Environment Research Council, London

Crooks JA (1998) Habitat alteration and community-level effects of an exotic mussel, Musculista senhousia. Mar Ecol Prog Ser 162:137-152

Crooks JA (2002) Characterizing ecosystem-level consequences of biological invasions: the role of ecosystem engineers. Oikos 97:153-166

Crooks JA (2008) The role of exotic marine ecosystem engineers. In: Rilov G, Crooks JA (eds) Biological invasions of marine ecosystems: ecological, management, and geographic perspectives. Springer, Heidelberg, p 287-304

Fauchauld K (1977) The polychaete worms, definitions and keys to the orders, families, and genera. Natural History Museum of Los Angeles County, Science Series 28:1-188

Fauchald K, Jumars PA (1979) The diet of worms: a study of polychaete feeding guilds. Oceanogr Mar Biol Annu Rev 17:193-284
Floerl O, Pool TK, Ingles GJ (2004) Positive interactions between non-indigenous species facilitate transport by human vectors. Ecol Appl 14:1724-1736

Grabowski JH, Powers SP (2004) Habitat complexity mitigates trophic transfer on oyster reefs. Mar Ecol Prog Ser 277:291-295

Grosberg RK (1981) Competitive ability influences habitat choice in marine invertebrates. Nature 290:700-702

Grosholz ED, Ruiz GM, Dean CA, Shirley KA, Maron JL, Connors PG (2000) The impacts of a nonindigenous marine predator in a California bay. Ecology 81: 1206-1224

Hacker SD, Madin LP (1991) Why habitat architecture and color are important to shrimps living in pelagic Sargassum: use of camouflage and plant-part mimicry. Mar Ecol Prog Ser 70:143-155

Harder T (2009) Marine epibiosis: concepts, ecological consequences and host defense. In: Flemming H, Venkatesan R, Snyutha Murthy P (eds) Marine and industrial biofouling. Springer, Berlin, p 219-231

Hedge P, Kriwoken LK (2000) Evidence for effects of Spartina anglica invasion on benthic macrofauna in Little Swanport Estuary, Tasmania. Ecology 25:150-159

Heiman KW, Vidargas N, Micheli F (2008) Non-native habitat as home for non-native species: comparison of communities associated with invasive tubeworm and native oyster reefs. Aquat Biol 2:47-56

Holloway MG, Keough MJ (2002) Effects of an introduced polychaete, Sabella spallanzanii, on the development of epifaunal assemblages. Mar Ecol Prog Ser 236:137-154

Jones CG, Lawton JH, Shachak M (1997) Positive and negative effects of organisms as physical ecosystem engineers. Ecology 78:1946-1957

Kochmann J, Buschbaum C, Volkenborn N, Reise K (2008) Shift from native mussels to alien oysters: differential effects of ecosystem engineers. J Exp Mar Biol Ecol 364: $1-10$

Krug PJ (2006) Defense of benthic invertebrates against surface colonization by larvae: a chemical arms race. In: Fusetani N, Clare AS (eds) Progress in molecular and subcellular biology. Springer, Heidelberg, p 1-53

Levine JM, Vila M, D'Antonio CM, Dukes JS, Grigulis K, Lavorel S (2003) Mechanisms underlying the impacts of exotic plant invasions. Proc Biol Sci 270:775-781

Ling SD (2008) Range expansion of a habitat-modifying species leads to loss of taxonomic diversity: a new and impoverished reef state. Oecologia 156:883-894

Martin-Smith KM (1993) Abundance of mobile epifauna: the role of habitat complexity and predation by fishes. J Exp Mar Biol Ecol 174:243-260

McCarthy JM, Hein CL, Olden JD, Van der Zanden MJ (2006) Coupling long-term studies with meta-analysis to investigate impacts of nonnative crayfish on zoobenthic communities. Freshw Biol 51:224-235

Mercer JM, Whitlatch RB, Osman RW (2009) Potential effects of the invasive colonial ascidian (Didemnum vexillum Kott, 2002) on pebble-cobble bottom habitats in Long Island Sound, USA. Aquat Invasions 4:133-142

Nydam M, Stachowicz JJ (2007) Predator effects on fouling community development. Mar Ecol Prog Ser 337:93-101

Orth RJ, Heck KL, von Montfrans J (1984) Faunal communities in seagrass beds: a review of the influence of plant structure and prey characteristics on predator-prey relationships. Estuaries 7:339-350

Osman RW, Whitlatch RB (1995) The influence of resident adults on recruitment: a comparison to settlement. J Exp Mar Biol Ecol 190:169-198 
Parker IM, Duffy JE, Orth RJ (1999) Impact: toward a framework for understanding the ecological effects of invaders. Biol Invasions 1:3-19

Perrett LA, Johnston EL, Poore AGB (2006) Impact by association: direct and indirect effects of copper exposure on mobile invertebrate fauna. Mar Ecol Prog Ser 326:195-205

Rilov G, Crooks JA (2008) Biological invasions of marine ecosystems: ecological, management, and geographic perspectives. Springer, Heidelberg

Rodriguez LF (2006) Can invasive species facilitate native species? Evidence of how, when and why these impacts occur. Biol Invasions 8:927-939

Rodriguez SR, Ojeda FP, Inestresa NC (1993) Settlement of benthic marine invertebrates. Mar Ecol Prog Ser 97: 193-207

Ruiz GM, Fofonoff P, Carlton JT, Wonham MJ, Hines AH (2000) Invasion of coastal marine communities in North America: apparent patterns, processes, and biases. Annu Rev Ecol Syst 31:481-531

Russo AR (1991) Do predatory fishes affect the structure of an epiphytal amphipod assemblage on a protected algal reef in Hawaii? Hydrobiologia 224:185-192

Schmidt AL, Scheibling RE (2006) A comparison of epifauna and epiphytes on native kelps (Laminaria species) and an invasive alga (Codium fragile spp. tomentosoides) in Nova Scotia, Canada. Bot Mar 49:315-330

Schwindt E, Iribarne OO (2000) Settlement sites, survival and the effects on benthos of an introduced reef-building polychaete in a SW Atlantic coastal lagoon. Bull Mar Sci 67: 73-82

Editorial responsibility: Richard Osman,

Edgewater, Maryland, USA
Simberloff D (1995) Why do introduced species appear to devastate islands more than mainland areas? Pac Sci 49: $87-97$

Stachowicz JJ (2001) Mutualism, positive interactions, and the structure of ecological communities. Bioscience 51: $235-246$

Stachowicz JJ, Byrnes JE (2006) Species diversity, invasion success, and ecosystem functioning: disentangling the influence of resource competition, facilitation, and extrinsic factors. Mar Ecol Prog Ser 311:251-262

Stachowicz JJ, Whitlatch RB (2005) Multiple mutualists provide complementary benefits to their seaweed host. Ecology 86:2418-2427

Stachowicz JJ, Fried H, Whitlatch RB, Osman RW (2002) Biodiversity, invasion resistance and marine ecosystem function: reconciling pattern and process. Ecology 83: 2575-2590

Taylor RB, Steinberg PD (2005) Host use by Australasian seaweed mesograzers in relation to feeding preferences of larger grazers. Ecology 86:2955-2967

Wahl M (1989) Marine epibiosis. I. Fouling and antifouling: some basic aspects. Mar Ecol Prog Ser 58:175-189

Wikström SA, Kautsky L (2004) Invasion of a habitat-forming seaweed: effects on associated biota. Biol Invasions 6: 141-150

Yurkonis KA, Meiners SJ, Wachholder BE (2005) Invasion impacts diversity through altered community dynamics. J Ecol 93:1053-1061

Submitted: July 8, 2009; Accepted: September 28, 2009 Proofs received from author(s): December 15, 2009 